\title{
Políticas de Inclusão Social do Acesso à Banda Larga: Histórias do Sul da Ásia*
}

Social Inclusion Policies for Broadband Access: Stories from South Asia

Helani Galpaya**

Seminário:

Alternativas para o desenvolvimento da infraestrutura e do acesso em

banda larga

Local: BNDES, Edifício Sede, Brasília, DF

Realização: Secretaria de Assuntos Estratégicos (SAE)

Palestra ministrada em 16 de novembro de 2009

Slides da palestra disponíveis no sítio eletrônico www.getel.org

A LIRNEAsia é uma organização regional de pesquisa que congrega estudiosos da Ásia e Pacífico com o objetivo de catalisar a transformação de regimes de regulação e políticas de tecnologias da informação e comunicação em regiões emergentes da Ásia e Pacífico. Essa rede atua no sudoeste da Ásia, em mais ou menos onze países.

Falarei sobre o que realmente aconteceu, e o que o governo pôde fazer ou não, bem como sobre a política de serviço universal no Sri Lanka e em alguns outros países da região.

Propus-me a falar sobre o programa de serviço universal do Sri Lanka, porque tem a ver com políticas de inclusão para acesso a tecnologias de informação e comunicação em banda larga. Acesso para quê? Para entretenimento? Para transparência? Para serviços governamentais? A intenção certamente é de se comunicar outras coisas; não apenas melhorar o acesso.

Em 2002 e 2003, o governo do Sri Lanka, fazendo uso de fundos do Banco Mundial, implantou o que, na época, era um programa de

*Desgravação, tradução e adaptação para a língua portuguesa de André Moura Gomes.

** Diretora de Operações e Especialista de Indicadores da LIRNEasia, onde coordena pesquisa sobre indicadores do setor de telecomunicações e de tecnologias da informação e comunicação. Mestre em tecnologia e política pelo MIT. Foi responsável pela implementação do Centro de Informações Governamentais do ICTA, órgão máximo de formulação de políticas de TIC do Sri Lanka.

Revista de Direito, Estado e Telecomunicações, v. 2, n. 1, p. 189-196 (2010) 
desenvolvimento eletrônico intersetorial muito amplo. Chamava-se "e-Sri Lanka (e-SL)".

$\mathrm{O}$ projeto tinha componentes múltiplos, como se pode ver nos slides. $\mathrm{O}$ fundamento último do programa era a expansão da infraestrutura de informação, ou seja, de backbone, pontos de acesso, quiosques, telecentros, e outros elementos de infraestrutura disponíveis em língua local. Outras dimensões do projeto relacionavam-se com aplicativos de governo eletrônico.

A partir da garantia de acesso, a pergunta que se faz é: o que as pessoas farão com ele? Espera-se que elas tenham serviços, como serviços de governo eletrônico. O projeto também enfocou o desenvolvimento da capacidade de recursos humanos em geral em tecnologias da informação e comunicação (TIC), especialmente no setor privado, criando-se um mercado de serviços de tecnologias da informação (TI) no Sri Lanka. Em outra frente, o projeto preocupou-se com aplicações sociais, como conteúdo nacional, acesso a pessoas com necessidades especiais, e, é claro, com o importante componente de liderança política.

Tudo isso é relevante porque o e-Sri Lanka lidava com a criação de um meio ambiente em que eram criadas, pela primeira vez, as condições básicas para a instituição de leis de transição quanto a questões de propriedade intelectual, já que o tema não vinha contemplado pela legislação do Sri Lanka até então.

Os efeitos do projeto têm sido lentamente percebidos. O componente mais relevante desse programa de governo no Sri Lanka é a iniciativa de governo eletrônico. Tem havido muita reengenharia e priorização de programas e os serviços que nós pensamos que tinham maior impacto, tais como obtenção de identidade, passaporte, carteira de motorista, coisas que a maioria das pessoas precisam ter ao longo de sua vida, foram automatizados e repensados para possibilitar o acesso dos cidadãos a tais utilidades. Enquanto a classe média talvez tenha acesso a computador no trabalho ou em casa, mais de um terço da população do Sri Lanka somente tem acesso a serviços de tecnologias da informação através de telecentros, ou seja, os quiosques de internet.

Hoje, cinco ano após o início do projeto, há um serviço governamental em ação. Ele não está baseado na internet. Trata-se de um centro de informação do governo, em que se pode ligar para o número 199 para Revista de Direito, Estado e Telecomunicações, v. 2, n. 1, p. 189-196 (2010)

DOI: https://doi.org/10.26512/lstr.v2i1.21687 
obtenção de informações sobre como obter um passaporte, impressão digital, dentre outros. Esse trabalho está progredindo, mas ainda há muito a ser feito. Graças à ação do governo, os serviços de tecnologias da informação de call centers têm progredido no tocante ao processamento de imagens médicas e terceirização de processos de negócios, assim como o desenvolvimento de produtos e serviços de tecnologias da informação, software e hardware.

Aqui chegamos à identificação de um aspecto chave do governo ao identificar o foco do setor de serviços de tecnologias da informação. O Sri Lanka está a $32 \mathrm{~km}$ da Índia e não é fácil competir com eles em nada. Eles produzem mais de 200 mil engenheiros; eles têm cientistas da computação e uma infraestrutura mais barata. Portanto, quando o projeto começou, a posição do Sri Lanka era muito específica. Íamos às empresas e dizíamos: nós somos um backup end, por assim dizer, dos seus negócios; venham para o Sri Lanka, abram um call center, façam o roteamento de suas ligações - de algumas de suas ligações; estamos ali para prover um serviço extra. E nós entendemos que nunca poderíamos competir em preços com a Índia.

Apesar dessa posição difícil, nós verificamos que o Sri Lanka tinha um diferencial quanto ao número de contadores, na medida em que nós enfocamos processos relacionados a contabilidade e terceirização. As empresas são selecionadas para esse nicho de mercado e financiadas pelo governo. São esses pequenos passos bem pensados que o governo do Sri Lanka implementou. Com isso, hoje, os serviços de tecnologias de informação ocupam o seu lugar nas exportações do Sri Lanka. Não é nada mau para um esforço de cinco anos, ou de dez anos se contarmos as empresas anteriores. No setor de serviços, tal atividade ocupa hoje o segundo lugar depois do turismo, com um crescimento acima de $22 \%$ ao ano.

Provavelmente esses números são pequenos comparados com o Brasil, mas eles significam empregos significativos para o Sri Lanka e diferenciados por sua produtividade, na medida em que alcançam o montante de onze mil dólares americanos por ano por empregado, afigurando-se como muito mais produtivo do que exportar mão-de-obra para o Oriente Médio - uma prática tradicional do Sri Lanka -, ou apostar no emprego em plantações de chá. Não podemos comparar o Sri Lanka com a Índia; podemos compará-lo com uma cidade da Índia. Assim, se tomarmos 
como base as cidades de Bangalore e Hyderabad, que inauguraram essa onda eletrônica muito antes, veremos que as condições eram muito semelhantes às do Sri Lanka, primeiramente porque a questão dos serviços envolveu o governo. No Sri Lanka, passou-se de uma empresa, que detinha um monopólio sobre os serviços de tecnologia de informação, para 33 licenças que foram outorgadas. Com isso, instaurou-se a competição no setor, mas, além disso, a presença de mais competidores aumentou em $20 \%$ a receita das ligações internas, não advindas dos telefonemas internacionais. Essa receita foi em parte reinvestida em backbones e pela primeira vez na história do Sri Lanka, temos uma rede de fibra óptica em construção por outra empresa que não o antigo monopólio. A partir daí, pode-se ir a uma empresa estrangeira e dizer: 'nós temos dois backbones, nós temos competição em nichos internacionais'. Esse grande esforço do governo atraiu o primeiro call center, que era do banco HSBC. Munidos da notícia de abertura do call center do HSBC, pudemos ir a outras empresas e dizer: 'a HSBC - uma empresa internacional - nos escolheu; venham vocês também para cá'. Para abrirmos esse nicho internacional, a redundância no backbone foi um fator chave.

Vejamos o que aconteceu com os telecentros. Havia um plano de estabelecer quinhentos telecentros, por intermédio de um modelo de negócios em que os empresários selecionados localmente teriam dinheiro, subsídio à conectividade e localização à porta de uma escola. Havia também um sistema que almejava os vouchers, que recebiam as crianças para acesso à banda larga. Dois anos depois de iniciado o projeto, o Primeiro Ministro, na época, percebeu que dois contratos haviam sido concedidos para empresários locais, que por acaso eram da oposição. Repentinamente, o assunto tornou-se muito politizado, alterando o modelo de negócios e resultando em autorização de ingresso somente a organizações sem fins lucrativos. Como resultado da politização do processo, o projeto de telecentros fracassou. Hoje, somente seis deles estão recebendo dinheiro em detrimento dos outros quinhentos, que provavelmente continuarão sem receber recursos. No que se refere à infraestrutura de redes do Sri Lanka, foi criado um plano para duas redes de backbone de fibra óptica, mas ambas fracassaram por vários motivos, resultando em processos judiciais contra os envolvidos. 
O projeto de governo eletrônico como um todo, entretanto, foi exitoso, pois, apoiado na função catalisadora do governo, permitiu um amplo desenvolvimento do setor privado. A rede de backbone tem sido um grande fracasso em relação ao que o governo pretendia fazer. Mas foi um grande sucesso no que se refere à redundância de backbone e à queda de preços. De forma semelhante, na rede de acesso, houve um grande fracasso em relação ao que o governo pretendia fazer, mas o acesso acontece.

No que diz respeito ao acesso, o Sri Lanka vivencia o que está acontecendo no Sul da Ásia em relação aos celulares. As pessoas da região têm acesso. Aqui [nos slides] temos alguns dos países com que trabalhamos. Fizemos uma pesquisa há algumas semanas sobre como as pessoas das classes D e E acessam os serviços. Mais de $86 \%$ das pessoas nos países do Sul da Ásia já fizeram ou receberam telefonemas nos últimos três meses, e uma porcentagem bem alta fez ligações nas últimas três semanas. Até mesmo na Índia rural (a mais rural possível) as pessoas estão telefonando; elas telefonaram ontem ... na última semana. Não há muita diferença entre o acesso urbano e rural. As pessoas compartilham telefones, o que faz com que não existam muitos assinantes, mas $46 \%$ das pessoas têm acesso a telefone. E se se levar em conta a possibilidade de compartilhamento de aparelhos, esse número cresce bastante. A área rural do Sri Lanka não é tão rural se comparada à área rural da Índia. $\mathrm{O}$ acesso rural está aumentando. Aqui [nos slides], entre 2006 e 2008, houve um aumento de $131 \%$ apenas na Índia rural. Trata-se de um crescimento democrático a preços acessíveis. Aqui [nos slides] nós temos dados de um custo total de celular. Na esquerda, nós temos Índia, Bangladesh, Paquistão, Sri Lanka dentre os mais baratos do mundo. Do outro lado está o Brasil: o mais caro. Não surpreende que os pobres urbanos e rurais usem serviços telefônicos no Sul da Ásia, onde é incrivelmente acessível, até mesmo se levada em conta a baixa renda da população. Essa é a primeira coisa que eu acredito que deve ser vista se nós formos pensar em acesso, seja de voz ou de dados.

Quando os dados foram divulgados em janeiro do ano passado [2008], a Nokia nos procurou e disse: "por que vocês têm preços tão baixos? Os reguladores devem ter feito algo incrível nesses países". Para saberem o que tínhamos feito, a Nokia nos contratou para realizarmos um estudo em que analisamos as regras do setor e vimos que não havia nada de especial nelas que justificasse o diferencial de preços. As regras de licitação não coibiram 
a profusão de procedimentos corruptos, com desequilíbrio de forças, muita ingerência política, pouca transparência. O diferencial, entretanto, foi que, no Sri Lanka, foi permitida a entrada das empresas de telecomunicações, gerando-se muita competição. Não fomos muito transparentes: nós nunca tivemos sequer um leilão. Nós sabemos que houve corrupção nos licenciamentos, algo infelizmente reconhecido publicamente. Mas mesmo em condições não transparentes, quando se dá acesso, as empresas entram com recursos e se for permitida a competição, as coisas começam a acontecer. Como o Mike Spence comentou, ao se crescer $8 \%$ a $9 \%$ por bastante tempo, tudo muda, e isso está acontecendo em um novo mercado. A transição nos leva a um ponto em que os preços são exeqüíveis, em especial se forem retiradas as barreiras para o capital estrangeiro. Isso aqui [nos slides] é no Paquistão, onde $30 \%$ do investimento direto estrangeiro vem do setor de telecomunicações e $64 \%$ do crescimento do investimento direto estrangeiro vem das telecomunicações. A receita, portanto, é permitir a entrada de capital estrangeiro e suspender as barreiras à entrada no mercado, permitindo um grande crescimento e lucros, embora não tanto quanto antes. Mesmo assim, o Sri Lanka hoje tem margens EBITDA comparáveis aos do ano passado na Europa e nos Estados Unidos.

As empresas têm ganhado dinheiro, algo em torno de dois a cinco dólares por mês por linha nessa faixa de renda. Trata-se, todavia, de um negócio sem nenhum risco de crédito. Não há o ônus de se ter que vender cartões, pois o crédito é diretamente colocado no aparelho. Nós temos compartilhamento de infraestrutura passiva, como também negociações regionais por equipamento, permitindo que os menores operadores também se beneficiem de economia de escala.

Outro aspecto relevante é que a qualidade do serviço é baixa. Nós temos redes altamente carregadas, o que assegura um preço muito mais baixo. Como estamos entrando no jogo das telecomunicações tarde podemos usar tecnologias mais baratas. Os licenciados podem utilizar aparelhos e estações de $2 \mathrm{G}$ e $3 \mathrm{G}$ por metade do preço dos que tiveram que instalar o $2 \mathrm{G}$ e depois passar para o 3G. Isso não se aplica somente para voz, mas também para dados. Esse é o caminho para a Ásia: ingressar no universo online por intermédio dos dispositivos móveis de redes 3G. Hoje, no Sri Lanka, há acessos pré-pagos 3G: a qualidade é menor, mas as pessoas estão conectadas. Para atingir conectividade universal na Ásia, será necessário ter Revista de Direito, Estado e Telecomunicações, v. 2, n. 1, p. 189-196 (2010)

DOI: https://doi.org/10.26512/1str.v2i1.21687 
todo tipo de banda larga: ADSL, cabo, e assim por diante. Poucos dos países asiáticos têm a conexão banda larga móvel. A Índia ainda não tem 3G. Há monopólio em algumas áreas, mas nas restantes não há 3G. Atualmente já se vê o uso de celulares para provimento de serviços de governo eletrônico, inclusive pagamentos. Há mais de 1,5 milhões de pessoas servidas por um único aplicativo.

Se concentrarmos nossa atenção na questão da influência de políticas públicas na expansão dos serviços, eu diria que elas não funcionam. $\mathrm{Na}$ Índia nós temos o segundo maior fundo de universalização. Esse fundo é contemplado com cinco por cento das receitas das operadoras de telecomunicações, mas o diferencial na zona rural se deveu à mobilidade: os melhores serviços pelos menores preços. Em outros países da região vê-se o mesmo comportamento, em que a regulação de serviços universais não funciona. Não funcionaram nas Filipinas, no Nepal, nem na Índia. No Sri Lanka, estamos tendo penetração muito alta. Assim, nas comunicações, é fundamental abrir o mercado para empresas privadas, mas não subestimar o poder do governo. Mesmo quando as iniciativas do governo falham, a difusão de consciência sobre sua importância adquire vida própria. Atualmente estamos com o projeto Bangladesh Digital. Para mim, é um programa mal concebido, que tenta repetir o e-Sri Lanka. Acredito que não chegará ao resultado desejado. Mas o que conseguimos alcançar é que quando falamos nesse tipo de programa o setor privado também deseja investir dinheiro nisso, as ONGs também querem investir nisso, gerando-se um efeito catalisador. O importante não é o que o governo faz, mas o que ele inicia. Os processos políticos têm uma vida própria. O papel do governo é de criar a demanda e as condições para a telecomunicação. Seu papel é importante. A entrada no mercado de serviços universais de telecomunicações é uma ferramenta de peso, e se o governo desejar tirar proveito da competição, não faça uso de políticas de serviço universal. Obrigada. 
